patient. The incision was made in the middle line patient. The incision was made in the middle line
between the umbilicus and pubes. No gas escaped on opening the peritoneum. The intestinal coil looked very healthy; there was no lymph or fæcal matter to be seen or smelt and no signs of peritonitis, either local or general, were present. On gently pulling out a few inches of small intestine a dark, highly infected patch was found which was the base of an ulcer formed only of peritoneum and apparently on the point of rupture. The intestines were gently passed on through the fingers and a few inches further up a perforation of the size of a pea was found, from which gas and a little yellowish, watery fluid could be expressed. Both ulcers were situated opposite the attachment of the mesentery; there were no signs of any lymph formation. The hole in the bowel was closed by inverting a portion about one inch long by means of Lembert sutures in the long axis of the bowel. Six sutures were introduced and the surface was sealed with collodion. The ulcer lower down, which was on the point of perforation, was then sutured in a similar manner for safety's sake, four sutures being introduced. No toilet of the peritoneum was made. The abdominal wound was closed with silkworm-gut sutures, all layers, including the peritoneum, being taken at cnce, and the dressing was applied. The operation was performed two hours after the onset of the abdominal symptoms. The patient stood it well and showed no signs of pain either during the incision through the abdominal wall or during the handling of the gut. She spoke several times during the operation and said that she felt no pain or discomfort. The pulse kept quite as good during the operation as it was previously to it. One hour after the operation the temperature was normal and the pulse was 100, thready, and thin, but regular. Five minims of solution of strychnia and a quarter of a grain of morphia were given hypodermically. On June 6th (the day after the operation) the temperature was normal and the pulse was from 120 to 130 , regular, and fairly full. There was no distension of the abdomen and no flatus was passed. The patient remarked that she felt much better. A rectal injection of four ounces of brandy and milk was given every six hours and 10 minims of solution of strychnia were given hypodermically morning and evening. On the 7 th the nurse reported that the patient's cough had been very troublesome during the early part of the morning, which caused her a good deal of abdominal pain. At 10 A.M. I found the abdomen distended, so I removed the dressings. The wound looked healthy; there was considerable tenderness on pressure all over the abdomen, the liver dulness was still absent, and no flatus had been passed. In consultation with my colleague (Dr. Thornton) we decided to give three grains of calomel with sulphate of magnesia every hour until the bowels were moved. After washing the rectum out with quantities of warm water a fair amount of semisolid frecs and a good deal of flatus were got rid of. On the 8th the patient had had a fair night. The cough was less troublesome and the abdomen was scarcely at all distended. The long rectal tube was passed and the bowel was washed out with warm water; this brought away a large amount of solid frces. The bowels acted once naturally in the afternoon and in the evening all distension of the abdomen had disappeared. The patient took her nourishment well by the mouth. From this date up to the time of her death, which took place on June 13th, eight days after the operation, the chief trouble to contend with was the condition of the heart and lungs. The pulse gradually got quicker, rising to from 150 to 160 daily in spite of all treatment, and the patient was much disturbed with cough and accumulation of secretions in the bronchi and inability to cough them up.

Necropsy.-A post-mortem examination was marle 16 hours after death. On opening the abdomen there were no signs of peritonitis or even fiuid in the peritoneal cavity. The omentum was slightly adherent to the incision in the abdominal wall, but there were no adhesions of the coils of the intestires either to each other or to the abdominal wall. The sutured portions of the gut were found to be quite air-tight and water-tight. The ulcer that had perforated was about three feet from the ileo-cæcal valve; several healed ulcers from the first attack and also the fresh ulcers of the relapse were found. On opening the chest a little clear fluid was found in both pleural cavities and also in the pericardial sac. Both lungs showed marked hypostatic pneumonia, nearly the whole of both lower lobes being consolidated. The heart muscle, even to the naked eye, was obviously much degenerated, the wall of the right ventricle being specially affected. The valves were normal.

Remarks. - The results of the post-mortem examination show that as regards the intestinal lesion the operation may be considered quite successful. It will be noticed that no general anssthetic was given, but an injection of eucaine was made in the line of the incision. The patient felt no pain or discomfort and it is obvious from the critical condition in which all such patients must necessarily be that the giving of a general anæsthetic adds materially to the risk of these operations.

Pretoria.

\section{THE COMPARATIVE VIRULENCE OF THE TUBERCLE BACILLUS FROM HUMAN AND BOVINE SOURCES.}

\author{
By MAZYCK P. RAVENEL, M.D.,
}

BACTERIOLOGIST OF THE STATE LIVE STOCK SANITARY BOARD OF PENNSYLVANIA ; LECTURER ON BACTERIOLOGY, VETERINARY DEPARTMENT, UNIVERSTTY OF PENNSYLVANIA.

\section{(From the Laboratory of the State Live Stock Sanitary Board of Pennsylvania.) \\ (Concluded from page $\$ 56$.)}

\section{Part II.-Testing the Pathogenic Power of Tuber-} culous Material of Human and Bovine ORIGIN.

IN addition to the study of a number of pure cultures obtained from man and cattle we have examined the pathogenic power of tuberculous material from the two sources also, making a series of inoculations which are as nearly parallel as possible. The results of these tests are shown in Table V. and Table VI. The plan was to inoculate a series of animals with tuberculous tissues rubbed into a smooth suspension, and at the same time and with the same material to inoculate a number of guinea-pigs which on their death would furnish material for another series of inoculations parallel with those made directly from the human and bovine tissues. It was believed that the material from guinea-pigs would more nearly represent pure cultures of the respective organisms than would be obtained from the tuberculous organs of man and cattle, and that the two sets of animals would lend themselves to an interesting comparison, besides fulfilling the primary object of comparing the virulence of human and bovine material. The plan was carried out for the bovine material, but failed for the human, as all the guinea-pigs died within 48 hours after inoculation. The second series of animals were inoculated with human material from another source and obtained at a later date. The results, while not entirely comparable, are nevertheless interesting and valuable.

Objections to the use of tuberculous material.-There are several disadvantages in using tuberculous material which were not overlooked in planning this work. 1 . It is impossible to give accurate doses, for although our suspensions may be made of an equal opacity, and counts of equal amounts show approximately the same number of bacilli, there is no way of determining what proportion of these bacilli are capable of multiplication. 2. Material from man almost always contains other bacteria. Our knowledge of mixed infections is too scanty to enable us to estimate the part played by these other species in determining the result, whether they inhibit or aid the action of the tubercle bacillus. The same is true of bovine material, although to a less extent, the tuberculous foci being more apt to remain inclosed. On the other hand, infection under natural conditions is always through such mixed material, and this method of inoculation approaches in some degree the conditions we meet in practice.

Souroe of bovine tuberculous material. - The bovine tuberculous material was obtained from a cow, six years old, which had shown symptoms of tuberculosis for a long time and was finally condemned and killed. At the necropsy the animal showed a generalised involvement of the thoracic cavity with some invasion of the abdominal organs. In the lungs but little tissue approaching normal was found and the pleuræ were studded with small nodules. Many of the tuberculous areas in the lungs had undergone caseation. 
Table V.-Showing Result of Inoculation of ANimals with Tuberculous Material from Botine and HuMAN SoURCES.

\begin{tabular}{|c|c|c|c|c|c|c|c|c|c|c|c|c|c|c|}
\hline \multirow{2}{*}{$\begin{array}{c}\text { Material. } \\
\text { Bovine. }\end{array}$} & \multirow{2}{*}{ 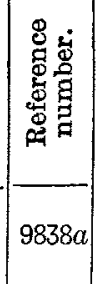 } & \multirow{2}{*}{$\begin{array}{c}\text { 离 } \\
\text { Hon } \\
\text { Horse. }\end{array}$} & $\begin{array}{c}\text { Date of } \\
\text { inoculation. }\end{array}$ & \multirow{2}{*}{$\begin{array}{c}\begin{array}{c}\text { Method } \\
\text { of in- } \\
\text { oculation. }\end{array} \\
\begin{array}{c}\text { Intra-pul- } \\
\text { monary. }\end{array}\end{array}$} & \multirow{2}{*}{$\begin{array}{c}\begin{array}{c}\text { Dose } \\
\text { in cubic } \\
\text { centi- } \\
\text { metres. }\end{array} \\
10\end{array}$} & \multicolumn{2}{|c|}{$\begin{array}{l}\text { Initial. } \\
\text { weight. }\end{array}$} & \multicolumn{2}{|c|}{$\begin{array}{l}\text { Weight at } \\
\text { death. }\end{array}$} & $\begin{array}{l}\text { Loss or gain } \\
\text { in weight. }\end{array}$ & Died. & Killed. & 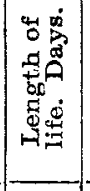 & 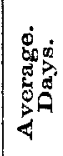 \\
\hline & & & July 14th. & & & 1205 & ounds. & $1010 \mathrm{p}$ & ounds. & $\begin{array}{l}195 \text { pounds } \\
\text { loss. }\end{array}$ & Sept. 6th. & - & 54 & \}$_{60}$ \\
\hline$"$ & $9840 a$ & ," & " 30th. & , & 10 & 1075 & ", & 1015 & $"$ & $\begin{array}{l}60 \text { pounds } \\
\text { loss. }\end{array}$ & - & $\begin{array}{c}\text { Nov. 14th, } \\
1899 .\end{array}$ & 66 & 1 \\
\hline , & 9701 & Pig. & , 14th. & $"$ & 4 & 130 & $"$ & 78 & , & $\begin{array}{l}52 \text { pounds } \\
\text { loss. }\end{array}$ & August $23 \mathrm{rd}$. & - & 40 & \\
\hline$\Rightarrow$ & 9702 & $"$, & " 14th. & $"$, & 4 & 131 & $"$ & 103 & ", & $\begin{array}{l}28 \text { pounds } \\
\text { loss. }\end{array}$ & Oct. 19th. & - & 97 & -503 \\
\hline$"$ & $9708 a$ & $"$ & "30th. & , & 5 & 94 & $"$ & 86 & $"$, & $\begin{array}{l}8 \text { pounds } \\
\text { loss. }\end{array}$ & Sept. 12th. & - & 44 & $v_{t}$ \\
\hline ", & $9706 a$ & $"$ & , 30th. & ", & 5 & 85 & $"$ & 72 & ", & $\begin{array}{l}13 \text { pounds } \\
\text { loss. }\end{array}$ & August 21st. & $\rightarrow$ & 22 & \\
\hline ", & $9697 a$ & Sheep & " 14th. & ", & 5 & 66 & $"$ & 49 & $"$ & $\begin{array}{l}17 \text { pounds } \\
\text { loss. }\end{array}$ & " 27th. & - & 44 & 88 \\
\hline ", & $9696 a$ & $"$ & " 30th. & $"$ & 5 & 71 & $"$ & 49. & $"$ & $\begin{array}{l}22 \text { pounds } \\
\text { loss. }\end{array}$ & , 31st. & - & 32 & \\
\hline$\because$ & $9841 a$ & Dog. & , 15th. & ", & 5 & $34 \frac{1}{2}$ & $"$ & 24 & ," & $\begin{array}{l}10 \frac{1}{2} \text { pounds } \\
\text { loss. }\end{array}$ & $\begin{array}{c}\text { Jan. 15th, } \\
1899 .\end{array}$ & - & 184 & $214 \frac{1}{2}$ \\
\hline , & $8010 a$ & , & , 30th. & , & 5 & 28 & ", & & - & - & - & $\begin{array}{c}\text { March 20th, } \\
1899 .\end{array}$ & 245 & \\
\hline 9 & $8089 a$ & Cat. & ", 18th. & ", & $2 \cdot 5$ & $2508 \mathrm{~g}$ & ammes. & $1695 \mathrm{gr}$ & ammes. & $\begin{array}{c}813 \text { grammes } \\
\text { gain. }\end{array}$ & August 18th. & - & 31 & 325 \\
\hline ," & $8001 a$ & $"$, & " 30th. & , & 5 & 1150 & $"$ & 1043 & ," & $\underset{\substack{\text { grammes } \\
\text { loss. }}}{107}$ & " 19th. & - & 20 & \\
\hline Human. & 8008 & Horse. & August 27th. & ," & . 10 & $1205 \mathrm{r}$ & ounds. & $1225 \mathrm{p}$ & punds. & $\begin{array}{c}20 \text { pounds } \\
\text { gain. }\end{array}$ & - & $\begin{array}{c}\text { March 14th } \\
1899 .\end{array}$ & 199 & $183 \frac{1}{2}$ \\
\hline , & 8088 & $"$, & Sept. 27th. & $"$ & 10 & 1200 & ," & 1370 & , & $\begin{array}{c}170 \text { pounds } \\
\text { gain. }\end{array}$ & - & $\begin{array}{c}\text { March 14th, } \\
1899 .\end{array}$ & 168 & \\
\hline , & 9704 & Pig. & August 27th. & , & 5 & 80 & $"$ & 100 & ", & $\begin{array}{l}20 \text { pounds } \\
\text { gain. }\end{array}$ & Dec. 9th. & - & 104 & \\
\hline$"$ & 9842 & , &,,$\quad 27 \mathrm{th}$ & ", & 5 & 91 &, & 91 & ", & - & Nov. 8th. & - & 73 & \\
\hline 9 & $9844 b$ & $"$, & Nov. 9th. & ", & 5 & 70 & , & 71 & , & 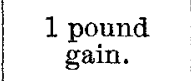 & Dec. 14th. & - & 35 & 588 \\
\hline$"$ & $8095 c$ & $"$ & Dec. 14th. & $"$ & 5 & & - & 193 & , & - & - & $\begin{array}{c}\text { March 21st, } \\
1899 .\end{array}$ & 97 & \\
\hline ", & $9705 b$ & , & Nov. 9th & , & 5 & 87 & ounds. & 107 & $"$ & $\begin{array}{l}20 \text { pounds } \\
\text { gain. }\end{array}$ & Dec. 7th. & - & 28 & \\
\hline ", & $8094 d$ & ", & Dec. 7 th. & " & 5 & & - & & - & - & , 20th. & - & 13 & \\
\hline$"$ & 9698 & Sheep. & August 27 th. & $"$ & 5 & 70 & ounds. & $74 \mathrm{p}$ & ounds. & $\begin{array}{l}4 \text { pounds } \\
\text { gain. }\end{array}$ & - & $\begin{array}{c}\text { March 17th } \\
1899 .\end{array}$ & 202 & \}$_{202}$ \\
\hline$"$ & 9699 & ", & ", 27th. & " & 5 & 58 & $"$ & 79 & $"$ & $\begin{array}{l}21 \text { pounds } \\
\text { gain. }\end{array}$ & - & $\begin{array}{c}\text { March 17th, } \\
1899 .\end{array}$ & 202 & \\
\hline , & 12179 & Dog. & Sept. 8th. & " & 5 & 55 & $"$ & 28 & " & $\begin{array}{l}27 \text { pounds } \\
\text { loss. }\end{array}$ & - & $\begin{array}{c}\text { March 25th } \\
1899 .\end{array}$ & 229 & $\{146$ \\
\hline ", & 12180 & ", & August 27th. & , & 5 & 29 & $"$, & 32 & $"$ & $\begin{array}{l}3 \text { pounds } \\
\text { gain. }\end{array}$ & Oct. 29 th. & - & 68 & \\
\hline$"$, & 10023 & Cat. & "27th. & , & $2: 5$ & $2190 \mathrm{~g}$ & ammes. & & - & - & August 29th. & - & - & \\
\hline$"$, & 10060 & , & Sept. 8th. & " & 5 & & - & & - & - & $\begin{array}{c}\text { March 20th, } \\
1899 .\end{array}$ & - & 193 & \\
\hline $\begin{array}{l}\text { Human } \\
\text { sputum. }\end{array}$ & 5984 & Calf. & July 29 th. & $\begin{array}{l}\text { Intra-peri- } \\
\text { toneally. }\end{array}$ & 10 & $108 p$ & unds. & $258 \mathrm{p}$ & ounds. & $\begin{array}{l}150 \text { pounds } \\
\text { gain. }\end{array}$ & - & $\begin{array}{c}\text { Jan. 14th, } \\
1899 .\end{array}$ & 169 & \\
\hline , & 8499 &, & , 29th. & ," & 10 & 131 & , & 265 & , & $\begin{array}{l}134 \text { pounds } \\
\text { gain. }\end{array}$ & - & $\begin{array}{c}\text { Jan. 14th, } \\
1899 .\end{array}$ & 169 & \\
\hline$"$ & 8049 & ", & May 16th. & , & 10 & & - & 340 & $"$ & - & - & $\underset{1898 .}{\text { August }}$ 1st, & 77 & \\
\hline ", & 8050 & ", & , 16th. & , & 10 & & - & 190 & $"$ & - & - & $\underset{1898 .}{A}$ & 77 & 132 \\
\hline$"$ & 8074 & $"$, & Oct. 18th. & $\begin{array}{l}\text { Fed } 11 \\
\text { times. }\end{array}$ & 30 to 60 & $224 \mathrm{pc}$ & unds. & 385 & , & $\begin{array}{l}161 \text { pounds } \\
\text { gain. }\end{array}$ & - & $\begin{array}{c}\text { Feb. 18th, } \\
1899 .\end{array}$ & 123 & $10 Q_{2}$ \\
\hline$"$ & 8096 & ", & , 18th. & , & 30,60 & 230 & , & 350 & , & $\begin{array}{l}120 \text { pounds } \\
\text { gain. }\end{array}$ & - & $\begin{array}{c}\text { Feb. 18th, } \\
1899 .\end{array}$ & 123 & \\
\hline$"$ & $9843 e$ & $"$ & August 2nd. & $\begin{array}{l}\text { Intra-peri- } \\
\text { toneally. }\end{array}$ & 20 & & , & & - & - & - & $\begin{array}{l}\text { Jan. 10th, } \\
1899 .\end{array}$ & 161 & \\
\hline ", & $9846 f$ & ", & , $\quad 2 n \mathrm{~d}$. & , & 20 & 132 & ", & & - & - & - & $\begin{array}{c}\text { Jan. 10th, } \\
1899 .\end{array}$ & 161 & \\
\hline
\end{tabular}

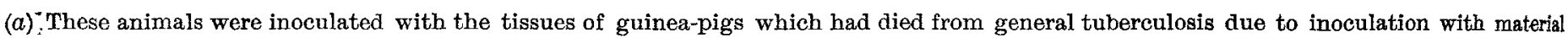
from a tuberculous cow. This material was the same as that used for the inoculation of the other animals. (b) Inoculated from tissues of pig 9842. (c) Inoculated from tissues of pig 9844. (d) Inoculated from tissues of pig 9705 . (e) Inoculated from tissues of calf 8049 . ( $f$ ) Inoculated from tissues of calf 8050 . 
The mediastinal glands were enormously enlarged and were caseous. Scattered over the peritoneum were many nodules. The liver was considerably involved and the portal and mesenteric glands were enlarged and caseous. Other abdominal organs showed no microscopic lesions. Nodules were taken from the pericardium, mediastinal and mesenteric glands, the lung, and the pleura. After thorough trituration in a mortar, each part separately, they were mixed, sterile water was added, and the whole was strained through cheese cloth. With this material a series of animals was inoculated and at the same time a number of guineapigs. These all contracted tuberculosis, four dying on the fifteenth day. Portions of their organs were prepared in the same way and were used for the inoculation of a second series of animals. (See Table V.)

Sources of human tuberculous material.-This material was obtained from three bodies, the lungs only being used. Two of the three were cases of well-marked acute miliary tuberculosis, the other a case of chronic phthisis ; all adults. The material was prepared for injection in the same way as described for the bovine, the suspension being made as nearly of the ssame thickness as possible. The first series of animals was jinoculated with the tissues from one of the cases of acute miliary tuberculosis on August 27th. A number of guineapigs were also inoculated with the object of having their tissues for a second series of inoculations, as with the bovine material, but they all died from septicæmia within 48 hours, preventing the execution of this plan. With the exception of the pigs and the calves inoculated with sputum the other amimals were inoculated from the two cases mentioned above. (See Tuble V.)

Method of inooulation. - In all the animals the injection was made into the lung, the field of puncture being shaven, washed with soap-and-water, next with alcohol and ether, and lastly with a 1 in 1000 solution of bichloride of mercury. The site of puncture was for the horses between the eighth and ninth ribs; for the pigs, sheep, and dogs between the sixth and seventh ribs; and for the cats between the fifth and sixth ribs.

The following are condensed post-mortem notes of the animals which were inoculated :-

Horses.-Two animals were inoculated with bovine material. One died after 54 days, with a loss of 195 pounds ; the other was killed after 66 days, having lost 60 pounds. In both the disease was mainly in the thoracic cavity. In the one inoculated with material direct from the cow both lungs were involved throughout. In the other the tuberculous process was confined to the lung into which the injection was made and was marked only near the site of inoculation. Two animals were inoculated with human material. Both had to be killed. One was entirely normal, not even the point of inoculation being discernible. In the other the tuberculous process was confined to an area five cubic centimetres in diameter, with the point of inoculation as a centre.

Pigs.-Four animals were inoculated with bovine material. All died in an average period after infection of $50 \frac{3}{4}$ days. The two which received the bovine material direct lived $68 \frac{1}{2}$ days, as against 33 days for those inoculated from the guinea-pigs. In all of them the lungs were the chief seat of the disease, all showing an acute miliary tuberculosis of both organs. In the two inoculated directly from the cow the abdominal rcavity was invaded to a limited extent, tubercle being seen only in the mesenteric glands. Six animals were inoculated with human material. Five died and one was killed. The average length of life of the two inoculated directly from man was $88 \frac{1}{2}$ days; for the three inoculated with tissues of other pigs which died the average was 22 days. In the first two the lungs were invaded throughout with miliary tubercles and one showed areas of pneumonic character. In neither was the abdominal cavity involved. Of the four pigs inoculated with material from the other pigs which had succumbed to inoculation with human tissues three presented a diffuse tuberculous pneumonia, rapidly fatal, one living only 13 days. The remaining animal was normal with the exception of the right lung and pleura. Both visceral and parietal pleuræ were largely covered with nodules from two millimetres to 12 millimetres in diameter, many of them caseous. The lung was dense throughout and contained many caseous areas, most marked near the surface.

Sheep.-Two animals were inoculated with bovine material. Both died, the one inoculated directly with bovine material in 44 days and the other in 32 days. Both were considerably emaciated and in both the disease was confined almost entirely to the thoracic cavity, the spleen being the only abdominal organ involved, and this only slightly so. In both the lungs showed hepatisation, more marked in the one inoculated with the tissue of the guinea-pig. Two animals were inoculated with human material. Both were killed 202 days after inoculation. One was entirely normal with the exception of an area in the right lung five centimetres in diameter at the point of inoculation, in the centre of which was a caseous abscess, the pus containing many tubercle bacilli. The second animal was normal throughout.

Dogs. - Two animals were inoculated with bovine material. The dog which received the bovine material direct became markedly ill, much emaciated, and died after 184 days. The pleural surfaces of both lungs were covered with minute nodules and were almost completely consolidated. In the right lung at the point of inoculation was a small abscess 2.5 centimetres in diameter. The dog inoculated with tissues from the guinea-pig showed little effect from it and was killed after 245 days. The only lesion found was an abscess cavity 12 millimetres in diameter at the point of inoculation in the right lung, scrapings from the wall of which contained many tubercle bacilli. Two animals were inoculated with human material. One was killed after 229 days. The only evidence of disease was the presence of rumerous minute nodules on the pleural surfaces of both lungs and a few on the pericardium. The lungs were otherwise normal. 'The second dog began to cough after six weeks, lost flesh rapidly, and died on the sixty-third day. Both pleuræ contained six ounces of sanguinolent pus. The lungs were the seat of an extensive miliary tuberculosis and at the point of inoculation in the right lung was an abscess cavity seven centimetres long by 2.5 millimetres in diameter. The abdominal organs were not involved.

Cats. - Two animals were inoculated with bovine material. Both became rapidly ill, one dying in 20 days and the other in 31 days. In both the lungs were the seat of an acute miliary tuberculosis. In the one which received the bovine material direct the spleen contained a number of cheesy areas. In the other the mesenteric glands were enlarged and cheesy. The more rapid progress of the disease in the latter was probably due to its smaller size and the larger dose. Two animals were inoculated with human material. One cat died after two days and has not therefore been included in the averages. The second was killed after 193 days and was found to be normal throughout. Not even the point of inoculation could be determined.

Summarising these cases, 12 animals were inoculated with bovine material. 10 of these died, while two survived-the horse and the dog, which received the tissues of the guineapigs. 14 animals were inoculated with the human material, of which eight died and six were killed. For most of the animals the tuberculous material direct from the cow seemed to be the more virulent. The sheep and pigs were exceptions to this-the pigs notably so, those receiving the tissues of guinea-pigs dying in 33 days, as against $68 \frac{1}{2}$ days for the others. The averages of life after inoculation given in the table, as well as the greater mortality, show strikingly the increased potency of the bovine material over that from man. This difference is further brought out by the extent and character of the lesions produced by the one and the other, as shown in the post-mortem notes above and in Table VI.

Infection of oalves with human tuberculous sputum.-The results of this experiment are included in Table V., the details, which are of considerable interest, being supplied here.

A calf (5984), aged five weeks, weight 108 pounds, was inoculated intra-peritoneally with 10 cubic centimetres of sputum from an advanced case of tuberculosis at the University Hospital on July 29th, 1898. The patient from whom the sputum was obtained was a young adult who had been ill for about one and a half years, and had been expectorating freely for one year. A cavity had been observed in the left lung about eight months before the sputum was obtained. Death occurred soon after. Beyond some slight elevation of temperature this calf showed no effect whatever from the inoculation. On Nov. 3rd it was tested with tuberculin but gave no reaction. When it was killed on Jan. 14th, 1899, it weighed 256 pounds, an increase of 150 pounds. It was in good condition and showed no tuberculous lesions in any part of the body. The site of inoculation could not be determined.

A calf (8499), aged five weeks, weight 131 pounds, was inoculated on July 29th, 1898, with 10 cubic centimetres of sputum of a patient at the University Hospital. This patient was an adult male, a miner by occupation. $\mathrm{He}$ 
Table VI. -Showing Comparative Extent of Lesions Produced by Inoculation of human and Bovise MATERTAL.

\begin{tabular}{|c|c|c|c|c|c|}
\hline - & & Bovine material direct. & $\begin{array}{l}\text { Bovine material passed } \\
\text { through guinea-pigs. }\end{array}$ & Human material direct. & $\begin{array}{l}\text { Human material passed } \\
\text { through other animals. }\end{array}$ \\
\hline Horses & $\ldots$ & $\begin{array}{l}\text { Extensive disease of thoracic } \\
\text { cavity. }\end{array}$ & $\begin{array}{l}\text { Extensive involvement of } \\
\text { lungs. }\end{array}$ & $\begin{array}{l}\text { One horse limited involvement of } \\
\text { one lung. The other was normal } \\
\text { throughout. }\end{array}$ & - \\
\hline Pigs & $\cdots$ & $\begin{array}{l}\text { Extensive disease of thoracic } \\
\text { cavity. }\end{array}$ & $\begin{array}{l}\text { Extensive disease of thoracic } \\
\text { cavity. }\end{array}$ & $\begin{array}{c}\text { Extensive disease of thoracic } \\
\text { cavity. }\end{array}$ & $\begin{array}{l}\text { Rapidly fatal ; very acute pro- } \\
\text { cess confined mainly to lungs. } \\
\text { Slower process in one, con- } \\
\text { fined to lung and pleura of } \\
\text { one side. }\end{array}$ \\
\hline Sheep & $\ldots$ & $\begin{array}{l}\text { Extensive disease of thoracic } \\
\text { cavity. }\end{array}$ & $\begin{array}{c}\text { Extensive disease of thoracic } \\
\text { cavity. }\end{array}$ & $\begin{array}{l}\text { Limited involvement of one lung } \\
\text { and pleura of same side in one } \\
\text { animal. The other normal } \\
\text { throughout. }\end{array}$ & - \\
\hline Dogs & $\ldots$ & $\begin{array}{l}\text { Extensive disease of thoracic } \\
\text { cavity. }\end{array}$ & $\begin{array}{l}\text { Limited involvement of one } \\
\text { lung, }\end{array}$ & $\begin{array}{l}\text { Limited involvement of pleura and } \\
\text { pericardium in one animal. In the } \\
\text { other extensive disease of thoracic } \\
\text { cavity. }\end{array}$ & - \\
\hline Cats & .. & $\begin{array}{l}\text { Extensive disease of thoracic } \\
\text { cavity and spleen. }\end{array}$ & $\begin{array}{l}\text { Extensive disease of thoracic } \\
\text { cavity and mesenteric } \\
\text { glands. }\end{array}$ & Normal throughout. & - \\
\hline
\end{tabular}

had been under treatment for nine months. At this period the apices of both lungs were consolidated. He had a cough for two years, lost flesh, and had one severe hæmorrhage. He expectorated a large amount of muco-purulent sputum. This calf showed an elevation of temperature which continued ulmost without intermission for three months, reaching as high as $105.8^{\circ} \mathrm{F}$. in August and September. On Nov. 3rd it was tested with tuberculin and gave a reaction. It was killed on Jan. 9th, 1899, weighing 265 pounds-an increase in weight of 134 pounds. It was in fair condition. There was a nodule in the peritoneum at the site of inoculation. In the omentum were numerous calcareous nodules of the size of a hazel nut and one softened nodule of the size of a hen's egg, which contained inspissated purulent material, and five smaller ones of the same character. The lungs, liver, and spleen were normal, but on the pleural surface of the diaphragm there was a deposit of fibrin which contained several well-defined nodules. On the abdominal surface of the diaphragm was a small amount of grape formation.

A calf (8049), aged about four weeks, was inoculated on May 16th, 1898, intra-peritoneally, with 10 cubic centimetres of sputum from an advanced case of pulmonary tuberculosis at the University Hospital. The sputum contained many bacilli. Beyond a slight cough, which was noticed in July, it showed no symptoms of discomfort and grew rapidly. It was tested with tuberculin on July 30th and gave good reaction. It was killed on August 1st; its weight was 340 pounds and its cordition was good; there was a large amount of fat. On the surface of both lungs and on the pleural surface of the diaphragm was a fibrinous deposit. In the cervical lobe of the right lnng a few small nodules were found on section. The mediastinal and bronchial glands were somewhat enlarged. The omentum contained a few nodules, and one, about one inch in diameter, which had undergone softening, the contents being rich in tubercle bacilli. The spleen showed a number of nodules. About one-half of the mesenteric glands were enlarged and showed cheesy degeneration. An emulsion from the centre of the softened nodule in the omentum and from portions of the spleen was made and 20 cubic centimetres injected intra-peritoneally into another calf four weeks old, weight 108 pounds, on August 2nd. Beyond a slight cough, noticed on Oct. 10th, the animal showed no ill-effects from inoculation. It was killed on Jan. 10th, 1899 ; its condition was good. The omentum was adherent to the peritoneum at the point of inoculation and contained some 10 nodules of about the size of a pea. In every other respect the animal was entirely normal.

A calf (8050), aged four weeks, was inoculated on May 16th, 1898, with sputum from an early case of pulmonary tuberculosis at the University Hospital. The sputum contained a large number of tubercle bacilli. Soon after inoculation the temperature of the calf rose and continued high, with some remissions, until it was killed. Its appearance was bad, the coat was dry and rough and the respiration was rapid. It was tested with tuberculin, but the temperature was too high for results. It was killed on August 1st, weighing 190 pounds. On the surface of both lungs there was a slight deposit of fibrin and on section a number of hemorrhagic areas were observed in both. The mediastinal and bronchial glands were enlarged and congested. The abdominal cavity contained about 12 ounces of bloody serum. The peritoneum was thickly studded over its entire surface with nodules from one millimetre to 12 millimetres in diameter, fibrous in character. In many places these nodules had massed together, forming tumours, some five centimetres in diameter, which were dense and fibrous. The spleen cortained many nodules both on the surface and throughout its substance The whole omentum was thickly studded with nodules from two millimetres to 12 millimetres in diameter: besides these there were three large masses, dense and fibrous in character, two of which were 15 centimetres long by seven centimetres wide, and 12 millimetres thick; and the third seven centimetres long, by six centimetres wide, by four centimetres thick. The abdominal surface of the diaphragm was thickly studded with nodules, fibrous in character. The mesentery was thickened and contained many nodules of small size. The appearance was that of a typical case of grape or pearl disease. The mesenteric and mediastinal glands were enlarged and somewhat caseous. 20 cubie centimetres of an emulsion made from these glands, which contained a large number of tubercle bacilli, were injected on August 2nd into the peritoneal cavity of another calif, four weeks old, weight 132 pounds. The animal showed no illeffects whatever from inoculation and was killed on Jan. 10th, 1899. A careful post-mortem examination showed it to be normal in all respects.

Summarising these cases, four calves of nearly the same age received intra-peritoneally 10 cubic centimetres of human tuberculous sputum from different sources, but in all cases containing a large number of tubercle bacilli. One showed. no ill effect from the injection except a slight rise of temperature, and when killed the necropsy was entirely negative. Of the other three, two had persistent high temperature following the injection, but only one showed marked illness otherwise. Post-mortem examination proved that all had become infected with tuberculosis, the lesions in two being quite extensive. From each of these two a second calf was inoculated intra-peritoneally with an emulsion made from well-developed nodules. In both cases the emulsion was rich in tubercle bacilli and a large dose-20 cubic centimetreswas injected. The result was absolutely negative in one animal and practically so in the other. Since both calves received a much larger number of tubercle bacilli in the emulsion than those injected with the sputum we are led to conclude that the result in the latter was due to a mixed infection which operated to the advantage of the tubercle bacillus. The attempt to infect calves with human sputum by the digestive tract failed wholly Two young calves (Table V., Nos. 8074 and 8096) were given from 30 cubic centimetres to 60 cubic centimetres of sputum containing many tubercle bacilli on 11 days. Some disturbance of digestion resulted at the time, but when killed no trace of tuberculosis was detected. ${ }^{1}$

1 This experiment was conducted by Dr. W. G. Shaw to whom all the credit is due. 
Indioations for further investigation.-In the further elucidation of this question cultures should be isolated from as many cases of primary intestinal tuberculosis as possible, and especially those cases in which there is reason to suspect infection by meat or milk. Having obtained the cultures it may well be asked whether or not we are in a position to determine positively the origin of the offending organisms. Are the differences which have been noted in culture, morphology, and virulence sufficiently marked and persistent to make differentiation possible? This I doubt. In my judgment much more work must be done before we are able to determine the origin of a given culture of the tubercle bacillus by examination of it in cultures. At present we know practically nothing of the influence of the human body on the tubercle bacillus, nor what changes may be induced in its morphology, cultural peculiarities, and virulence by residence in the human tissues, nor what length of time is necessary to induce such changes, if induced at all. In my studies I have, as shown in Table III., recovered the tubercle bacillus, both human and bovine, from horses, dogs, swine, goats, and in one instance had the rare, if not unique, opportunity of recovering the bovine organism from man after accidental inoculation. These recovered cultures have all been carefully compared with the originals, and while some differences have been observed and noted in the remarks following the table, with possibly one exception, they have not been of a marked or distinguishing character. In the case of the man the bacillus remained in his tissues from Jan. 1st to Feb. 27th-58 days. The recovered culture was practically identical with the original. This is, however, a shorter time by a great deal than elapses between intestinal infection in children through food and their death, and does not enable us to draw conclusions as to these cases. like the culture recovered from animals it indicates that the tubercle bacillus is, as a rule, quite tenacious of its characteristics. We have noted constantly that the bacilli found in scrapings from the various organs of the animals inoculated with bovine cultures have been long and beaded, though the culture used was of the short and unbeaded type. The recovered cultures, however, on blood serum have always resembled the original. In a series of examinations of material coughed up by cows I failed, in every case, to find bacilli of what has been described as the bovine type. In fact, the longest tubercle bacilli I have ever observed, except in old cultures, were seen in some specimens of this material. The virulence of this material was considerably greater than human sputum ordinarily is, though the comparison was not made with accuracy.

Retention of charactcristics in culture.-On blood serum with 5 per cent. of glycerine the tubercle bacillus from bovine sources will, as a rule, retain its morphological and cultural characteristics for a long time. Culture $H$ has now been grown for two years (July 6th, 1901) and is of the sixteenth generation. Beyond an increased vegetation no marked change can be detected in it. With a single exception (Culture F) the same may be said of all the cultures isolated. This culture was isolated with some difficulty, and so scant was the growth for six generations that I was several times on the point of abandoning it. Only in the sixth generation was growth enough obtained for experimental inoculation. Considerably more growth took place in the seventh, and the eighth grew luxuriantly, since which all sub-cultures have been abundant. From the eighth generation on serum cultures were made on 5 per cent. glycerine agar, and an abundant growth obtained on this medium in the first transfer. Coincident with this increase of vegetative power came a marked change in the morphology. From being short, thick, and staining evenly, it is now long, more slender than in the early growth, and shows marked beading. In other words, from being a typical "bovine" culture, it has during the past ten months so changed that it can now pass as a typical "hnman" culture. It will be observed, by reference to Table IV., that its pathogenic power for guineapigs and rabbits was not as great as is usually found in bovine cultures.

Culture in collodion sacs. - The method of culture in the borly of living animals, which has been productive of such brilliant results in the hands of the French, offers much assistance in the solution of the problem before us. It has enabled Focard ${ }^{2}$ to demonstrate the possibility of so modifying the mammalian tubercle bacillus that it becomes like the arian organism in culture and pathogenicity. We are now

${ }^{2}$ Annales de l'Institut Pasteur, vol, xii., No. 9, September, 1898. attempting to modify two feebly virulent human cultures by residence in the peritoneal cavity of cattle. Culture M was kept for seven months in the abdominal cavity of a heifer inclosed in collodion sacs, two sacs being used. On removing the sacs but little multiplication of the bacilli was noted. Cultures were recovered directly from the sacs. In the first transfer the cultures grew more rapidly and abundantly than the original culture, but the morphology of the individual bacilli cannot be said to have changed to a noticeable degree. The virulence was not increased. Rabbits were not killed by subcutaneous inoculation. Guinea-pigs died after an average of $42 \frac{1}{3}$ days. A calf inoculated intra-peritoneally showed no ill-effects and gave no reaction to tuberculin after seven weeks. Culture Nasua narica (coati) of Dr. Theobald Smith, inclosed in collodion sacs, was kept in the peritoneal cavity of a yearling heifer for 11 months. On removal there was considerable increase in the growth, especially in one sac. Cultures were recovered from the sacs and showed some marked changes, especially in the manner of growth. On both blood serum and glycerine agar the growth was most rapid, at least twice as rapid as usual for this culture. On serum it covered the surface in from seven to 10 days, as a thick, white, moist layer, almost cottony near the water at the bottom. On glycerine agar the growth was more dry and wrinkled, but very rapid. The bacilli stain more evenly and are, on the whole, shorter, though long forms are seen. Guinea-pigs and rabbits inoculated subcutaneously are still living after four months. A calf which received four cubic centimetres of a milky suspension in the jugular vein reacted to tuberculin after 10 weeks. The experiment is being continued, the culture recovered from the capsule having been placed again in the peritoneal cavity of another calf. No conclusions can be drawn as yet, though the indications are that both cultures have become less strictly parasitic rather than more so by the procedure.

\section{As To THE INTERPRETATION OF THE RESULTS OF THE EXPERIMENTS.}

Accepting it as proven that the bovine tubercle bacillus has, as a rule, considerably greater pathogenic power than the human bacillus for a large majority of experimental animals, how should we interpret this in regard to man? Is it fair to conclude that this increase of virulence will hold good for man also? Until the contrary is proven, or until good reason for believing the contrary is shown, it is, in $\mathrm{my}$ judgment, right that this conclusion be held, at least as a working hypothesis. I am aware of the objections to this view that will be raised by some and acknowledge freely that it cannot be accepted as conclusive. Virulence is no doubt a factor which is relative to the subject, and exaltation of virulence for one species does not necessarily prove an increased virulence for other species. Indeed, the reverse is true in some instances. ${ }^{3}$ However, it cannot be denied as a general rule that when the virulence of a pathogenic organism is increased for one animal it is increased for all that are naturally susceptible to its action.

'The tubercle bacillus is unique in the extent of its pathogenic activity, both by direct experimental inoculation as well as by infection under what may be considered more or less natural conditions. The list of animals in which tuberculosis has been observed in parks and zoological gardens is appalling, the discoveries of Dubard ${ }^{4}$ and others showing that not even the cold-blooded animals are exempt from this universal scourge. While it may be said of the tubercle bacillus that in cultures in the laboratory it is unusually tenacious of its characteristics, it is certain that in nature it has a wide range of adaptability as a pathogenic agent. Hence for the tubercle bacillus perhaps more than for any other known microbe we are justified in believing that an exaltation of virulence for practically all experimental animals will hold good in the case of man also.

The question can be determined definitely only by direct inoculation of man. To do this experimentally is, of course, impossible, consequently we are forced to rely for evidence of this nature on those accidental cases which occur from time to time. It has been my fortune to have three such cases come under my observation, in each of which the infecting organism was known positively to be of bovine origin.

3 The streptococcus is said to become increased in virulence for mice by successive passages through these animals, but less virulent for rabbits. 
Similar cases have been reported by Tscherning ${ }^{6}$ and Pfeiffer, ${ }^{7}$ the latter ending in general infection and death. To these may be added two cases observed by Dr. M. B. Hartzell ${ }^{3}$ of the University of Pennsylvania, though in both absolute proof of the bovine origin of the offending organism is lacking. Both occurred in healthy men employed by one of our large American railways to clean and repair cars used in the transportation of cattle. In both a well-developed tuberculosis of the skin followed slight wounds of the back of the hand inflicted by broken timbers. In one case the local disease was soon cured and no further trouble resulted. The other, however, ended fatally after about a year, through the infection becoming generalised, with involvement of the lungs. This patient was a robust man, 44 years old, weighing 175 pounds, with a good family and personal history. Dr. Hartzell felt able to exclude with reasonable certainty any other source of infection.

Cases such as these permit us to deny with authority the claim which has been made by certain persons that by long residence in animals of the bovine species the tubercle bacillus becomes so changed as to render it incapable of successful residence in the tissues of man. In all of these instances the bovine bacillus grew and multiplied under conditions known to be most unfavourable to it with the production of characteristic lesions and in two of the seven cases gained access to the internal organs causing death, a result which is unusual when the local lesion is due to infection from human sources. While the number of cases is too small to enable us to draw sweeping conclusions the indications are that by this mode of inoculation the pathogenic power of the bovine bacillus is at least as great as that possessed by itś human congener.

Infection through food. - It will not be necessary here to review at length the reported instances of infection through the digestive tract following the use of food products from tuberculous cattle. Most of these of necessity lack precision and are not absolutely demonstrative, though some of them have, as Nocard has said, "almost the value of an experiment." The well-known observations of Stang, ${ }^{9}$ Demme, ${ }^{10}$ Gosse, ${ }^{11}$ and Ollivier ${ }^{12}$ leave little doubt of the power of the bovine tubercle bacillus to infect man through the djgestive tract.

The evidence derived from the statistics of tuberculosis on this point is purely circumstantial yet of such strength as to be most convincing. The compilations of Dr. Tatham bring out most strikingly the fact that in early life some potent factor is at work in causing tuberculosis. In the Harben Lectures for 1898 Sir Richard Thorne speaks of this as follows: "So, also, if you will compare the rates in Tables $A, B$, and $C$ (pages 5,6, and 7), and contrast the reduction of 27.9 per cent. which bas taken place, under five years of age, during the last 45 years in all forms of tuberculous disease and that of 66 per cent. in phthisis with the corresponding one from tabes mesenterica, which only reached 3.0 per cent., you will see that in considering the latter cause of death we are dealing with a totally different state of affairs. ..... The matter, too, assumes a still more serious aspect if we limit ourselves to the first year of life when milk is most largely used as food, for then we find that the reductions in the rate of death from the various forms of tuberculosis, which reduction has been going on at 'all ages' for about half a century, not only disappears but is actually transformed into a large increase, reaching no less than 27.7 per cent. This in itself is grave enough, but its significance is still further emphasised when we remember what are the circumstances under which this increase in the rate of death from tabes mesenterica has gone on synchronously with a decrease in that from other forms of tuberculosis." Evidence of a similar nature is given by Dr. G. F. Still ${ }^{13}$ of the Hospital for Sick Children, Great Ormond-street, in bis analysis of 769 consecutive neeropsies of children under 12 years of age, 269 of which showed tuberculous lesions. Of these, 117 , or 43.5 per cent., were in children under two years old, while in the first three years of life 56.6 per cent., or more than a half of the total number, occurred. From his study of the lesions in these cases Dr. Still believes that in

6 Congrès pour l'Etude de la Tuberculose, first session, 1888.

7 Zeitschrift für Hygiene. Band iii., 1898

8 Journal of the American Medical Association, April 16th, 1898. 9 Nocard: Les Tuberculoses Animales. iv Ibid. 11 Ibid.

12 La Semaine Médicale, Feb. 25th, 1892. Paris Academy of Medicine.

13 Brit. Med. Jour., August 19th, 1899, and Journal of Comparative Pathology and Therapeutics, vol. xii., Part 4.
153 , or 56.8 per cent., the respiratory tract was the channel of infection, while in 63 , or 23.4 per cent, the alimentary canal was responsible, the remaining 53 cases being uncertain or otherwise accounted for. Accepting these figures as given they indicate strongly that milk, the most largely used food, has a considerable part in the spread of tuberculosis, and justify the conclusion quoted from a report made to the Council of the British Medical Association, that "the mortality from tuberculosis in early childhood is not decreasing as it is at other ages in the United Kingdom, and the opinion that this great prevalence of the disease in childhood is due to infection through the alimentary canal by milk from tuberculous cows appears to be well founded." From Germany come further confirmatory facts. Widerhofer gives an analysis of 418 cases of tuberculosis in children, showing among them 101 with involvement of the intestine. Of these, 43 , or 42.5 per cent., were between the ages of two and five years, the period of life when cow's milk forms a large part of the food for children.

\section{CONCLUSIONS.}

In view of the foregoing experiments and of the evidence quoted it seems justifiable to conclude :-

1. That the tubercle bacillus from bovine sources has in culture fairly constant and persistent peculiarities of growth and morphology by which it may tentatively be differen. tiated from that ordinarily found in man.

2. That cultures from the two sources differ markedly in pathogenic power, affording further means of differentiation, the bovine bacillus being very much more active than the human for all species of experimental animals tested, with the possible exception of swine which are highly susceptible to both.

3. That tuberculous material from cattle and from man corresponds closely in comparative pathogenic power to pure cultures of the tubercle bacillus from the two sources, from all animals tested.

4. That it is a fair assumption from the evidence at hand, and in the absence of evidence to the contrary, that the bovine tubercle bacillus has a high degree of pathogenis power for man also, which is especially manifest in the early years of life.

\section{ATYPICAL EMPYEMA IN GENERAL PRAC- TICE, WITH ILLUSTRATIVE CASES AND CRITICAL NOTES. ${ }^{1}$}

\section{BY C. C. BAXTER TYRIE, M.B., M C. EDIN.,}

LATE DEMONSTRATOR OF ANATOMY, SURGEONS' HALI. EDINBURGI, AND AT THE YORKSHIRE COLLEGE, VIOTORIA UNIVERSTTY.

THE very frequency of empyema invests the condition with a special interest to the general practitioner-an interest which is emphasised by its perversity in arising when it is least expected and its vagaries in running courses and achieving results which, to say the least, are disrespectful alike to teachers and text-books. The associated operation which is generally performed by the practitioner himself is not always followed by the expected result. Cases sometimes rapidly recover where we had little hope of such a result or, alas, they sometimes disastrously end where we were confident of a happy result. The following cases illustrate the varying behaviour of pleural effusions and the difficulties incident to their diagnosis and management.

CAsE 1.-A boy, aged seven years, with satisfactory family history and a previous record of good health, came under my care in March, 1900. His malady for the first five days presented the usual signs and ran the ordinary course of a sharp broncho-pneumonia. Resolution on the right side took place, but fluid appeared in the left pleural sac. On the eighth day an exploratory puncture disclosed some pus. On the tenth day the usual operation resulted in the withdrawal of half a pint of pus, the odour of which was more suggestive of ischio-rectal than pleural origin. An interval of three weeks found the discharge still copions and fotid, the temperature unpleasantly hectic in behaviour, the cough paroxysmal, and the expectoration

1 A paper read before the Bradford Medico-Chirurgical Society on June 18th, 1901. 